LA-UR- $98=4088$

Title:

\title{
STABILITY VERSUS FIRST STRIKE COSTS DURING DEEP REDUCTIONS
}

Author(s):

Gregory H. Canavan, P-DO

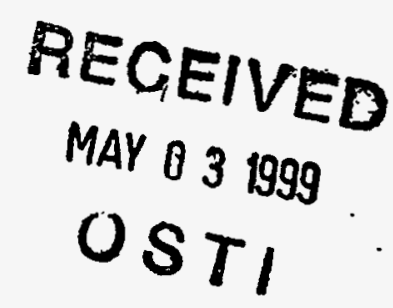

Submitted to:

For discussions outside the Laboratory

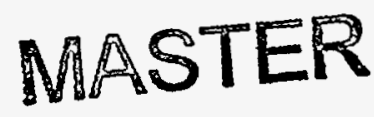

Date: 10 September 1998

DISTRIBUTION OF THIS DOCUAENT IS URHAMTEB

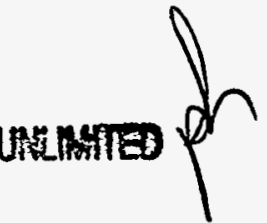

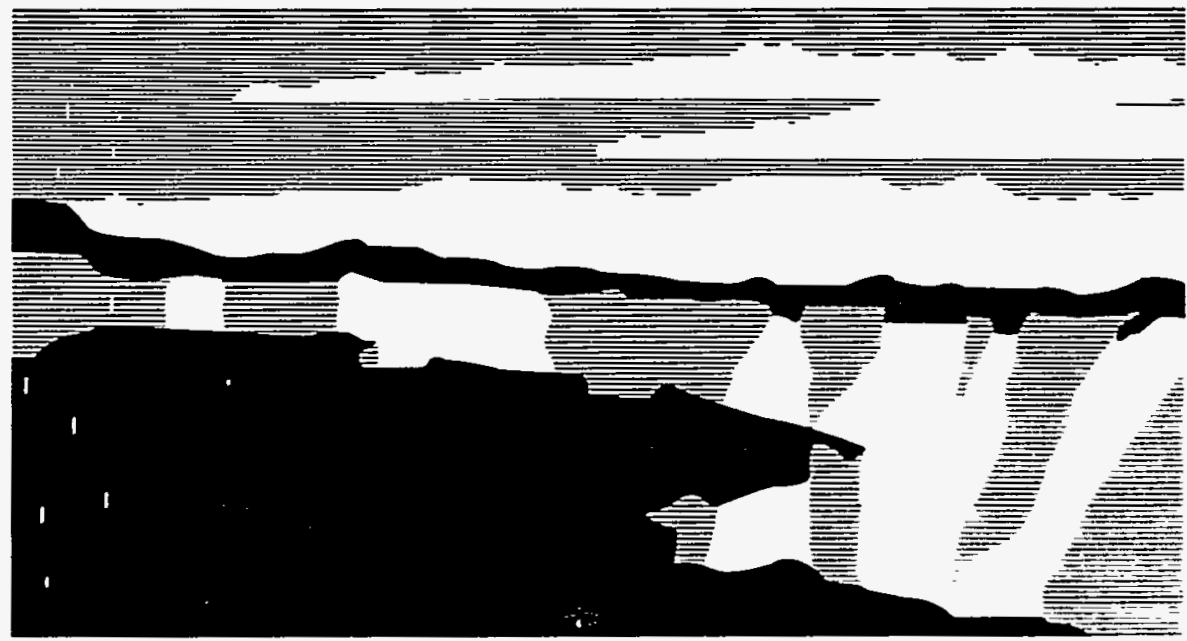

Los Alamos National Laboratory, an affirmative action/equal opportunity employer, is operated by the University of California for the U.S. Department of Energy under contract W-7405-ENG-36. By acceptance of this artic:le, the publisher recognizes that the U.S. Government retains a nonexclusive, royaity-tree license to publish or reproduce the published form of this contributiori, or to allow pthers to do so, for U.S. Government purposes. The Los Alamos National Laboratory requests that the publisher identify this article as work performed under the auspices of the U.S. Department of Energy. 


\section{DISCLAIMER}

Portions of this document may be illegible in electronic image products. Images are produced from the best available original document. 


\title{
STABILITY VERSUS FIRST STRIKE COSTS DURING DEEP REDUCTIONS
}

\author{
Gregory H. Canavan
}

\begin{abstract}
Reducing missile forces ultimately increases stability. However, for vulnerable forces, that increase is accompanied by an increase in first strike costs, which would disincentivize force reductions. For survivable forces there is a useful region in which weapon reductions could increase stability while reducing first strike costs.
\end{abstract}

The seminal paper by Piontkovsky and Skorokhodov ${ }^{1}$ considers the variation of stability during the transition from large to small missile forces and interprets it in terms of a "new paradigm" for the "transition from mutual assured destruction (MAD) stability towards mutual assured protection (MAP) stability." This note reviews that transition and extends it to survivable forces. It shows that for the vulnerable forces they studied, the increase of stability at small forces is largely a matter of the attacker running out of weapons, which could be eliminated by a reduction of the target set in proportion to the number of weapons. Moreover, it is accompanied with a large increase in first strike cost which should cause a potential attacker to oppose any reduction in the number of weapons.

If a large fraction of the missiles is survivable, second strikes approach first strikes, and the cost of damage to self decreases. Thus, the first strike cost also decreases, so it and the stability index are inversely correlated. Then, a potential attacker would have no reason to . oppose the reduction of $\mathrm{m}$. However, at very low force levels, the results reduce to the proportional and hence unstable relationship derived earlier for regional conflicts, which obtains during the buildup from very low force levels. Stability at low levels is sensitive to details of models, objectives, and target sets.

Analysis. The aggregated, probabilistic model used for the first, F, and second, S, strikes between two equal missile forces is described in Appendix A. They are converted into first and second strike costs $C_{1}$ and $C_{2}$ through approximations to the fractions of military value targets destroyed as described in Appendix B. The calculations below assume that each side has $\mathrm{M}=$ 500 weapons with $\mathrm{m}=1$ to 5 weapons per missile, which roughly spans START II conditions.

The principal variable in the analysis is $\mathrm{f}$, the fraction of weapons allocated to attacks on missiles, which Piontkovsky and Skorokhodov evaluate analytically and which is determined by numerical optimization below. Figure 1 shows the variation of $f$ with $\mathrm{m}$. The $\mathrm{f}_{\text {num }}$ determined by numerically minimizing the first strike costs of Eq. (B3) varies from $\approx 0.65$ at $\mathrm{m}=5$ to 0.72 at $\mathrm{m}$ $=2$, after which it falls to 0.58 at $\mathrm{m}=1$, reflecting a shift of weapons first to missiles when damage limiting is possible and then to value when it is not. The curve $f$ denoted by diamond 
symbols is from the analytic optimization studied in earlier papers. ${ }^{2}$ While it is $20-30 \%$ below $\mathrm{f}_{\text {num }}$ at large $\mathrm{m}$, it has the same trends and lies within about $10 \%$ for $\mathrm{m}<3$. However, this note wishes to study stability throughout the transition, so the numerical solution is used.

Figure 2 shows the first and second strikes, $\mathrm{F}$ and $\mathrm{S}$, that result from these allocations. As $\mathrm{m}$ decreases, $\mathrm{F}$ decreases proportionally, but $\mathrm{S}$ increases because suppression of second strike is less effective at low weapons levels.

Figure 3 shows the first strike cost $\mathrm{C}_{1}$. The bottom curve is the cost of damage to self from the increasing $\mathrm{S}$. The middle curve reflects the increasing cost due to the attacker's inability to meet his damage objectives as $m$ decreases. The top curve is their sum, which increases from $\approx 0.22$ at $m=5$ to 0.44 at $m=1$. Thus, the attacker sees first strike costs increase significantly and monotonically as $\mathrm{m}$ decreases. To prevent that increase, he would be expected to oppose a decrease in $\mathrm{m}$.

Figure 4 shows the variation of the cost of second striking second, $C_{2}$, i.e., the cost of not striking first, as a function of $\mathrm{m}$. The cost due to damage to self falls from $\approx 0.4$ to 0.12 as the attacker's weapons decrease from $m=5$ to 1 . Since the second strike increases, the cost of incomplete damage to other falls. Their sum falls from $\approx 0.7$ to 0.4 .

Figure 5 shows the costs $C_{1}$ and $C_{2}$ and the stability ratio $I=C_{1} / C_{2}$. As $C_{1}$ increases and $\mathrm{C}_{2}$ decreases as $\mathrm{m}$ falls, their ratio increases rapidly, reaching unity at $\mathrm{m} \approx 2$. For smaller $m$, there should be no strikes. However, while the first strike stability index is determined by $C_{1} / C_{2}$, the attacker's decision is determined by the minimization of $\mathrm{C}_{1}$ alone. Thus, the potential attacker would have an incentive to oppose the reduction of $m$ despite the fact that he would benefit from the increase in stability if it occurred.

Figure 6 shows this incentive graphically in the form of a plot of $I$ vs $C_{1}$ in which the points are labeled by the corresponding values of $\mathrm{m}$. The situation for START I corresponds roughly to $\mathrm{m}=3$. From a stability perspective, it would be desirable to move to $\mathrm{m}=1$ and $\mathrm{I} \approx$ 1.2 , but that would increase $C_{1}$ from $\approx 0.35$ to 0.45 , about $30 \%$. From the perspective of minimizing $\mathrm{C}_{1}$, the first striker would actually prefer to move to $m=5$ where $C_{1} \approx 0.2, a \approx 100 \%$ reduction. However, that would decrease $\mathrm{I}$ from $\approx 0.7$ to 0.3 , which would be $\mathrm{a} \approx 100 \%$ reduction in stability. The essential point is that for these conditions, first strike and stability considerations are in opposition. To the extent that military analysis relies on the former and political thought on the latter, military and political considerations are likely to be in opposition as well.

In interpreting the variation of stability during the transition from large to small missile forces in terms of a "new paradigm for the transition from MAD to MAP stability," Piontkovsky and Skorokhodov correctly analyze the optimal allocation of weapons for small forces and the stability indices they produced. However, they emphasize the result that stability increases as the number of weapons decreases, omitting discussion of the fact that this increase is primarily due 
to the attacker running out of weapons. If instead, the attacker concentrates his attack on the highest value sets, i.e., reduces $\mathrm{k}$ as $\sim 1 / \mathrm{M}$, that effect goes away. Moreover, they did not discuss the accompanying increase of first strike costs, which would be opposed logically on both sides. Thus, the work shows that force reductions are desirable, but does not discuss the forces that would be required to overcome the real and rational incentives that would oppose them.

Survivable forces. The analysis above assumes all missiles are vulnerable, a restriction that can be tested by assuming that each side also has $\mathrm{N}$ survivable missiles with $\mathrm{n}$ weapons each. The calculations assume $N=M=500$ and $n=m$ for each $m$. Figure 7 shows the resulting analytic and numerical allocations of weapons to vulnerable missiles, which are reduced from those of Fig. 2 by the ratio of vulnerable to total forces, peaking at about $35 \%$.

Figure 8 shows the resulting first and second strikes, which are much larger than those of Fig. 2 throughout. The most pronounced shift is in S, which is almost constant in Fig. 2, but which is almost as large as F in Fig. 8 due to the survivable retaliatory forces.

Figure 9 shows the first strike cost $C_{1}$. By contrast to the $C_{1}$ for vulnerable forces of Fig. 3, Fig. 9 shows that while the cost of incomplete damage to other still increases monotonically as $\mathrm{m}$ decreases, the cost of damage to self decreases due to the stronger damage limiting possible. Since the latter is dominant for $50 \%$ survivable forces, $\mathrm{C}_{1}$ also decreases slightly, which means that a potential attacker would have no reason to oppose the reduction of $\mathrm{m}$.

Figure 10 shows the second strike $\operatorname{cost} \mathrm{C}_{2}$. The survivable forces make second strikes larger and hence the costs of incomplete damage to other in striking second smaller at large $\mathrm{m}$, although the change is modest by $m=1$. The impact on the cost of damage to self is larger, ranging from $\mathrm{a} \approx 50 \%$ increase at $\mathrm{m}=5$ to a $300 \%$ increase in $\mathrm{m}=1$. However, the net effect is that $\mathrm{C}_{2}$ still falls about $25 \%$.

Figure 11 shows $C_{1}, C_{2}$, and $I=C_{1} / C_{2}$ for $50 \%$ survivable forces. The principal departure from Fig. 5 for vulnerable forces is that both $C_{1}$ and $C_{2}$ fall as $m$ decreases, and that $C_{1}$ falls more rapidly than $\mathrm{C}_{2}$ so that $\mathrm{I}$ increases slightly as $\mathrm{m}$ decreases. Thus, for this fraction of survivable forces, the reduction of $\mathrm{C}_{1}$ and the increase of $\mathrm{I}$ can be accomplished simultaneously by decreasing $\mathrm{m}$. That is shown more clearly in Fig. 12, which plots $\mathrm{I}$ as a function of $\mathrm{C}_{1}$ for $\mathrm{m}=$ 1 to 5 . For $m=5, I \approx 0.94$. As $m=3$ corresponds to 3,000 weapons, the decrease in $I$ as $m$ falls to 3 is related to the minimum in the transition from current to START III force levels discussed earlier ${ }^{3}$. The reduction from $m=5$ to 3 decreases $C_{1}$ but does not increase $I$, so it is not obviously desirable from a stability perspective.

The bulk of the increase in I occurs between $\mathrm{m}=3$ and 2; the further increase between $\mathrm{m}$ $=2$ and 1 would be for $I>1$ which is unphysical. Thus, the majority of the increase in I occurs between $M=3,000$ and 2,000 weapons, where numerical solutions are required. For smaller $M$, Fig. 7 shows that the analytic solution is adequate for predicting trends. There, earlier analyses ${ }^{4}$ 
show that $\mathrm{f}$ is independent of $\mathrm{M}, \mathrm{F} \sim 2 \mathrm{mM}$, and $\mathrm{S} \sim \mathrm{mM}$, so that $\mathrm{I} \sim \mathrm{S}-\mathrm{F} \sim \mathrm{mM}, \mathrm{C}_{1} \sim \mathrm{S}-\mathrm{LF} \sim$ $\mathrm{mM}$, and $\mathrm{I} \sim \mathrm{C}_{1}$, as discussed elsewhere. ${ }^{5}$ Thus, the region in $\mathrm{m}$ in which $\mathrm{C}_{1}$ decreases as $\mathrm{I}$ increases is bounded on both sides.

Summary and conclusions. Piontkovsky and Skorokhodov studied the variation of stability during the transition from large to small missile forces, interpreting it in terms of a "new paradigm" for the "transition from MAD stability towards MAP stability. This note reviews that transition and extends it to survivable forces. For the vulnerable forces they studied, the increase of stability at small forces is largely a matter of the attacker running out of weapons, which could be eliminated by a reduction of the target set in proportion to the number of weapons. Moreover, it is accompanied by a large increase in first strike cost which should cause a potential attacker to oppose any reduction in the number of weapons.

For forces of which a large fraction is survivable, second strikes approach first strikes, so the cost of damage to self decreases as additional damage limiting possible. Since the cost of damage to self is then dominant, the total $\mathrm{C}_{1}$ also decreases. Thus, $\mathrm{C}_{1}$ and the stability index $\mathrm{I}$ are inversely correlated, and a potential attacker would have no reason to oppose the reduction of $\mathrm{m}$ over a range of $m=2-3$. At lower force levels, the results reduce to the unstable $I \sim C_{1}$ relationship derived earlier for linear conditions, which obtains during the buildup from very low force levels, e.g., in regional conflicts. 


\section{APPENDIX A. EXCHANGE MODEL}

It is possible to model exchanges between equal missile missiles forces in terms of the first, $F$, and second, $S$, strikes one side could deliver. Each side has $M$ vulnerable missiles with $\mathrm{m}$ weapons each and $\mathrm{N}$ survivable missiles with $\mathrm{n}$ weapons each. The first striker allocates a fraction $f$ of his weapons to the other's vulnerable missiles, producing a first strike on value targets of

$$
F=(1-f)(m M+n N) .
$$

The average number of weapons delivered on each vulnerable missile is

$$
\mathrm{r}=\mathrm{f}(\mathrm{mM}+\mathrm{nN}) / \mathrm{M} \text {. }
$$

For $r$ large, the average probability of survival is approximately

$$
\mathrm{Q} \approx \mathrm{q}^{\mathrm{r}} \approx \mathrm{e}^{\mathrm{fW}} \mathrm{ln} \mathrm{q} / \mathrm{M} \text {, }
$$

where $q=1-p$, and $p$ is the attacking missile's single shot probability of kill, which is taken to be $\mathrm{p}=0.6$ for all missiles. The second strike is

$$
\mathrm{S}=\mathrm{mMQ}+\mathrm{nN} \text {, }
$$

which is delivered on value, as missiles remaining at the end of the exchange have no value.

\section{APPENDIX B. STRIKE COSTS AND STABILITY INDICES.}

These first and second strike magnitudes can be converted into first and second strike costs through exponential approximations to the fraction of value targets destroyed. The cost of damage to the side that strikes first is approximated by

$$
\mathrm{C}_{1 \mathrm{~s}}=\left(1-\mathrm{e}^{-\mathrm{kS}}\right) /(1+\mathrm{L}) \text {, }
$$

where the constant $\mathrm{k} \approx 1 / 1000$ is roughly equal to the inverse of the size of military value target set held at risk, and $L$ is a parameter. The cost of incomplete damage to one's opponent is approximated by

$$
\mathrm{C}_{10}=\mathrm{Le}-\mathrm{kF} /(1+\mathrm{L}) \text {, }
$$

which is small for $\mathrm{F}$ large and large for $\mathrm{F}$ small. $\mathrm{C}_{1 \mathrm{~s}}$ and $\mathrm{C}_{10}$ are formally incommensurate, as they represent damage to different parties, but a conventional approximation to a total cost for striking first is their weighted sum ${ }^{6}$

$$
\mathrm{C}_{1}=\mathrm{C}_{1 \mathrm{~s}}+\mathrm{C}_{1 \mathrm{o}}=\left(1-\mathrm{e}^{-\mathrm{kS}}+\mathrm{Le}^{-\mathrm{kF}}\right) /(1+\mathrm{L}),
$$

where $\mathrm{L}$ is a constant that represents the attacker's relative preference for inflicting damage on the other and preventing damage to self. $\mathrm{L}$ small means that the first striker is primarily concerned about denying damage; $L$ large means he is more concerned about inflicting damage 
on the other. The conventional assumption that $\mathrm{L} \leq 1$ and construction of $\mathrm{C}_{1}$ as a weighted average is plausible but not unique. Second strike costs are also composed of damage to self and other. The former is approximated by

$$
\mathrm{C}_{2 \mathrm{~s}}=\left(1-\mathrm{e}^{-\mathrm{kF}}\right) /(1+\mathrm{L})
$$

the latter by

$$
\mathrm{C}_{20}=\mathrm{Le}-\mathrm{kS} /(1+\mathrm{L})
$$

and the total cost for unprime striking second by

$$
C_{2}=C_{2 s}+C_{2 o}=\left(1-e^{-k F}+L e^{-k S}\right) /(1+L)
$$

There is some arbitrariness in converting $C_{1}$ and $C_{2}$ into stability indices. ${ }^{7}$ It is conventional to use the ratio of first and second strike costs, $I=C_{1} / C_{2}$, as a stability index, as when this index is large, there is no advantage to striking first. However, when it is small, there is an advantage, which may be perceived as an incentive to first attack in a crisis. 


\section{References}

'. A. Piontkovsky and A. Skorokhodov, "New Paradigm of Strategic Stability," A. Zichichi ed, International Seminar on Nuclear War and Planetary Emergencies (London, World Scientific, 1993).

2. G. Canavan, " Stability at Low Symmetric Force Levels," Los Alamos report LA-UR-97-3728, September 1977.

3. G. Canavan, "Considerations in Missile Reductions and Dealerting," L. Krueger ed, Proceedings of the World Federation of Scientists Working Group on Missile Proliferation and Defense (World Federation of Scientists, Lausanne, 1998); "Considerations in Missile Reductions and Dealerting," Los Alamos report LA-UR-98-1426, April 1988.

4. G. Canavan, " Stability at Low Symmetric Force Levels," op. cit.

5. G. Canavan, "Stability of Regional Configurations," A. Zichichi ed, International Seminar on Planetary Emergencies, 23rd Session World Scientific, London, 1998); Los Alamos report LAUR-97-, February 1997.

${ }^{6}$. G. Kent and R. DeValk, "Strategic Defenses and the Transition to Assured Survival," RAND Report R-3369-AF, October 1986.

7. G. Canavan, "Impact of Differing Metrics on Crisis Stability Analyses," A. Zichichi ed., International Seminar on Nuclear War and Planetary Emergencies, 18th Session: Global Stability Through Disarmament (London, World Scientific, 1993). 


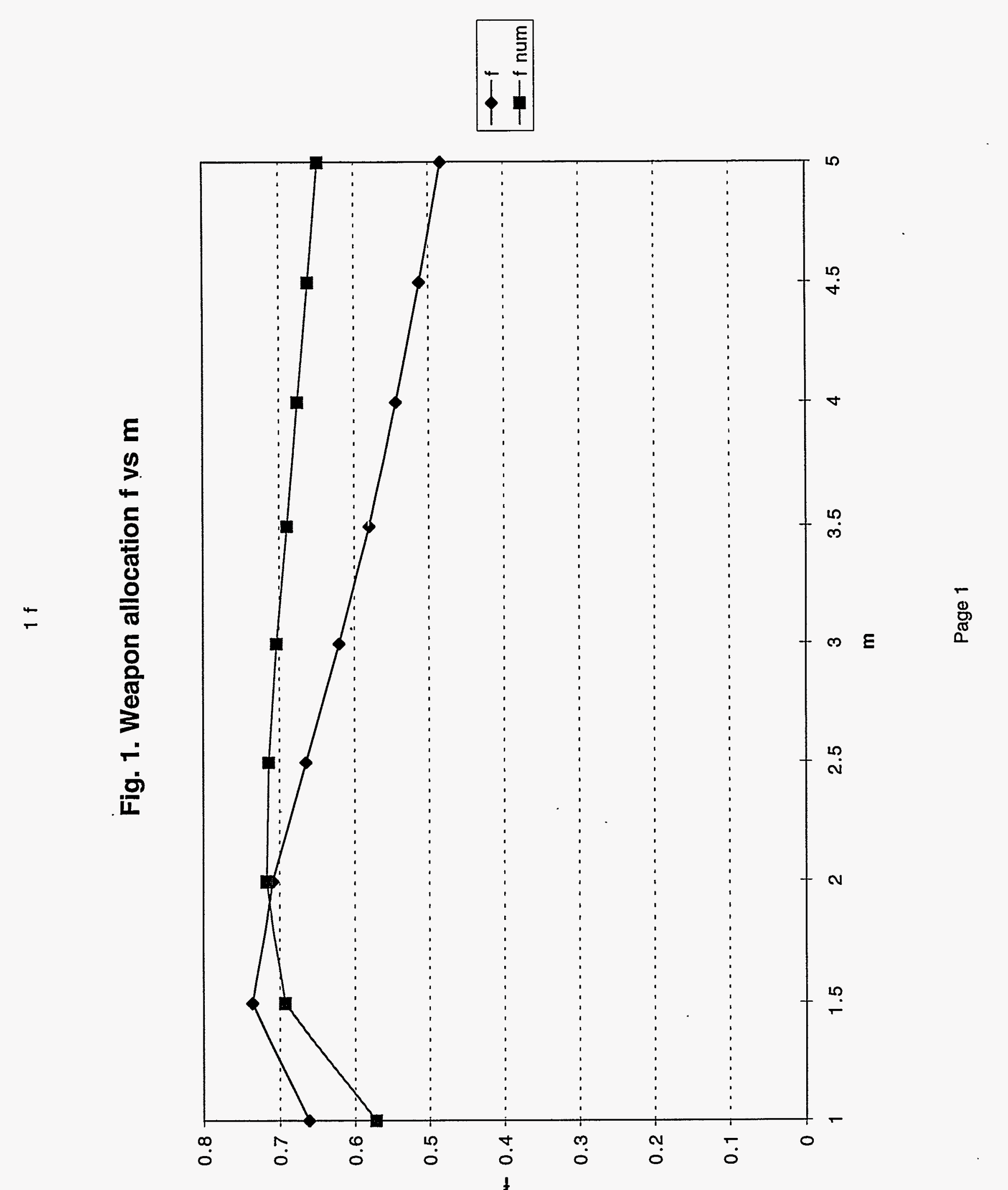




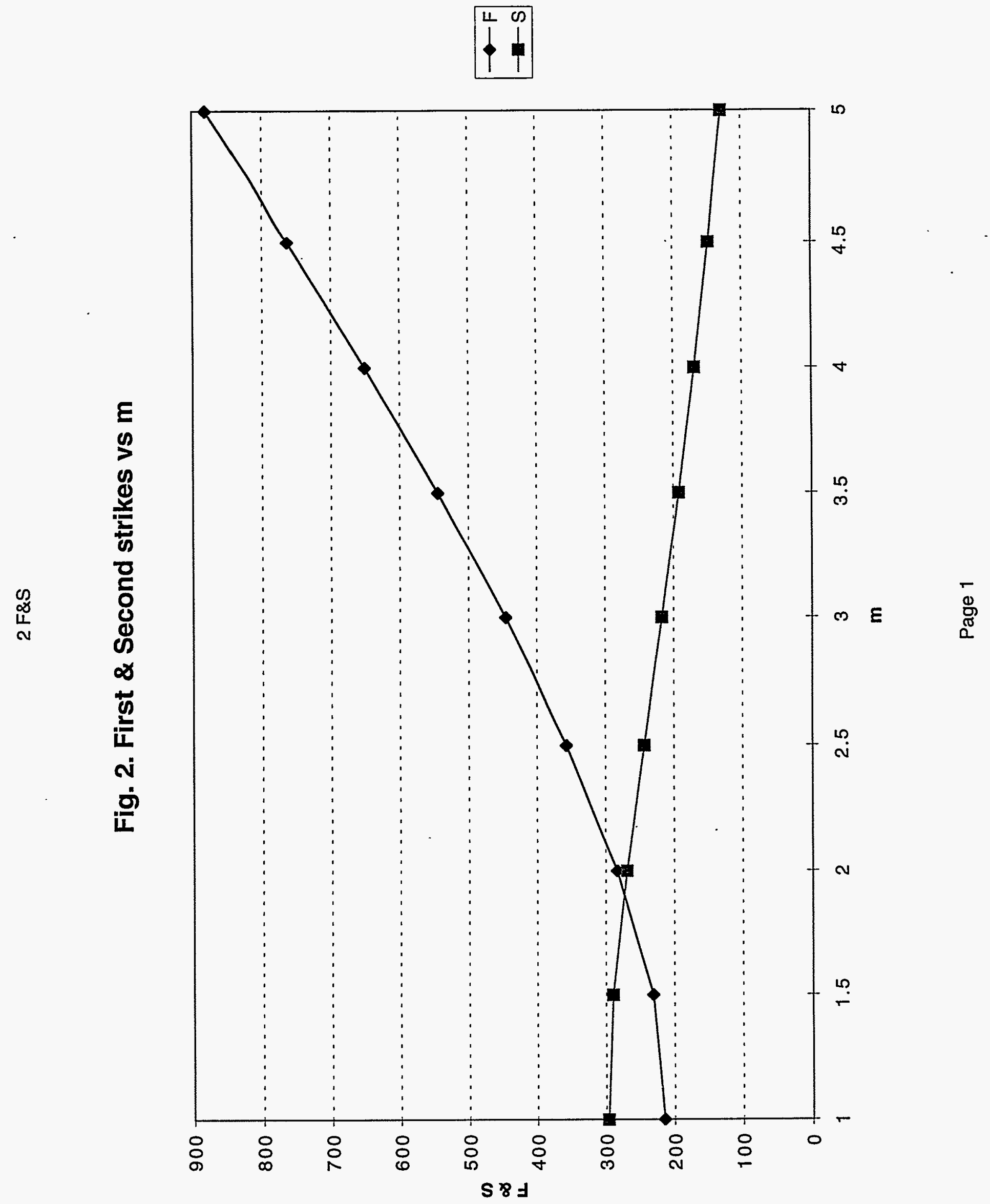



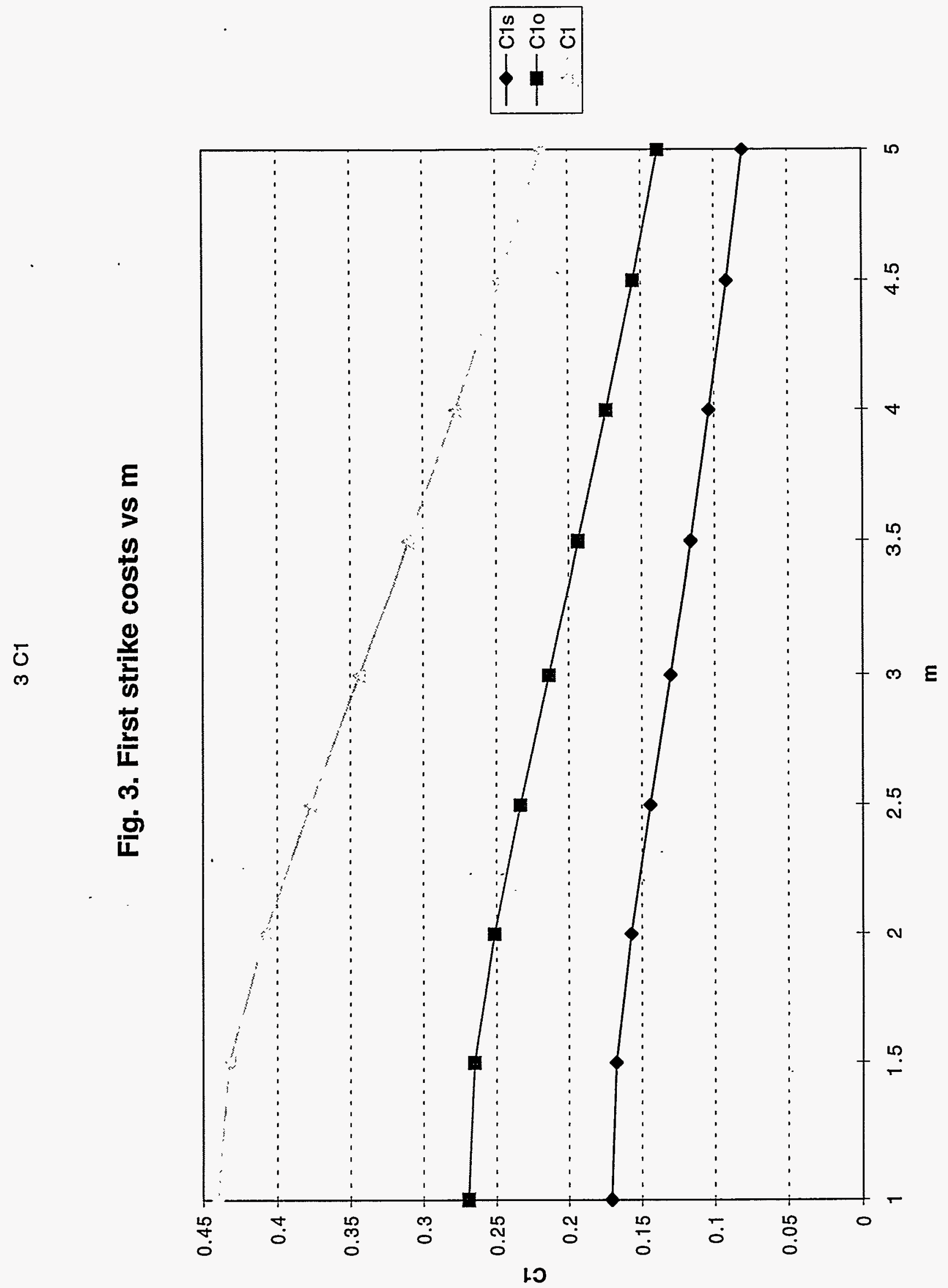

必 


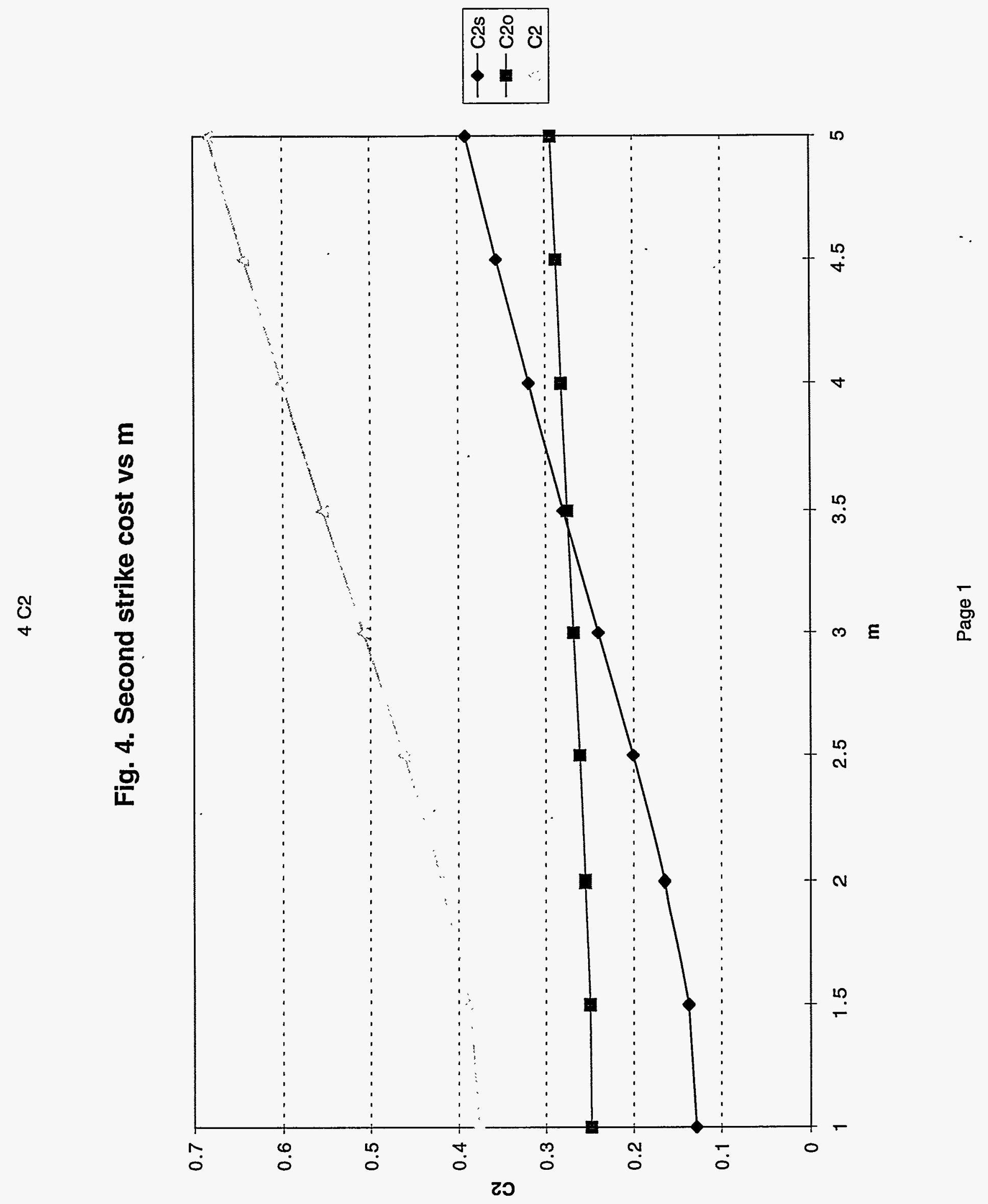




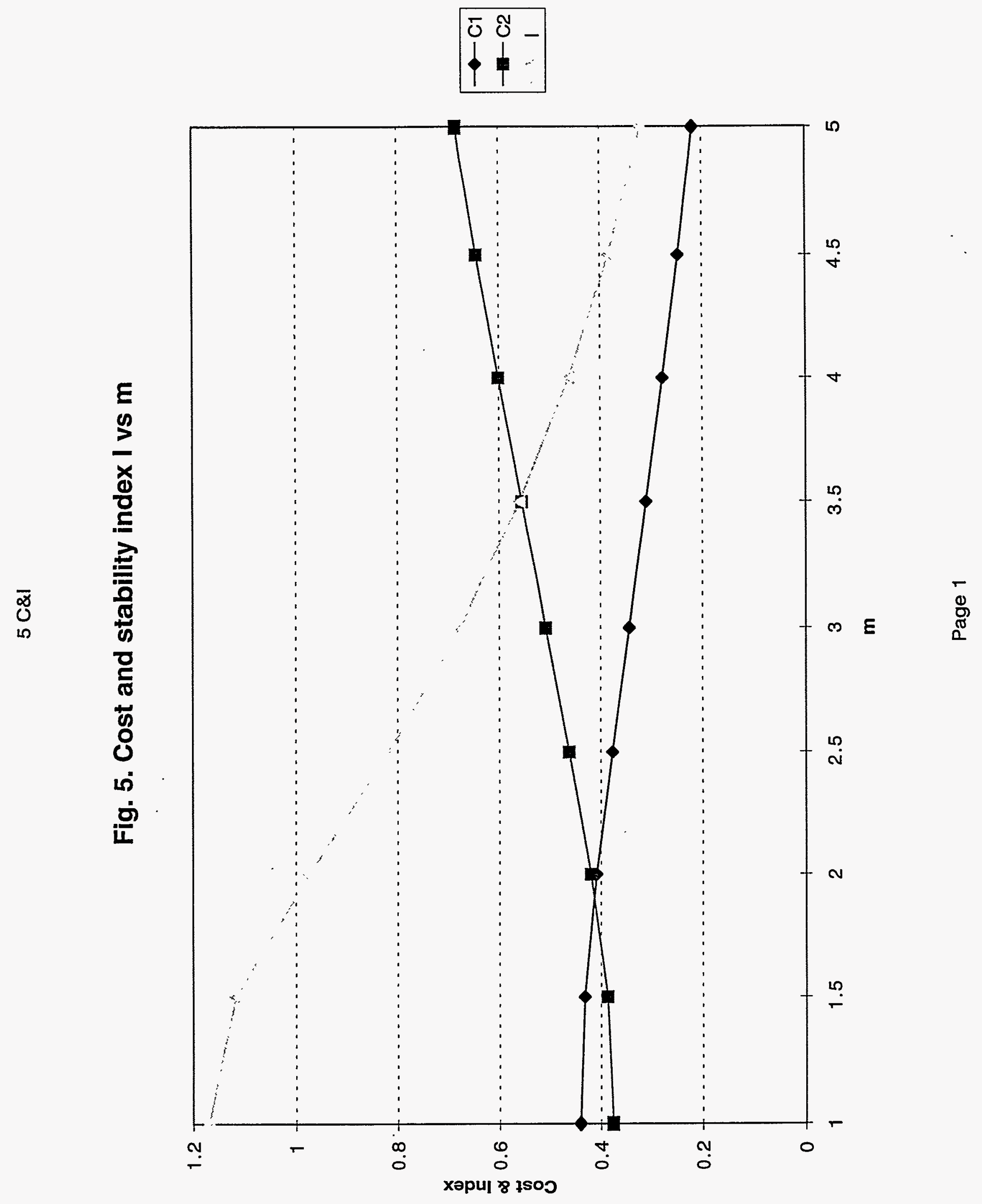




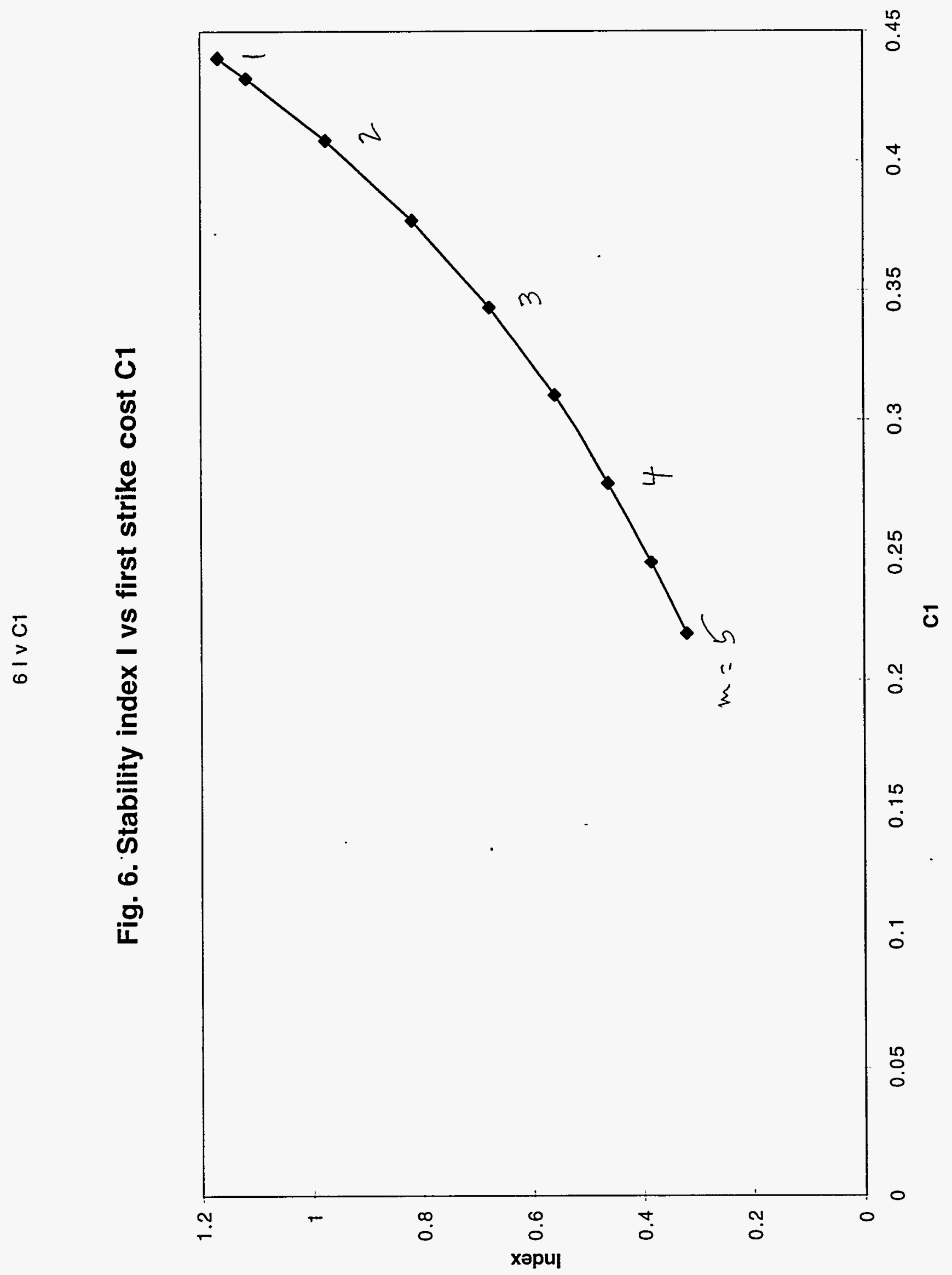




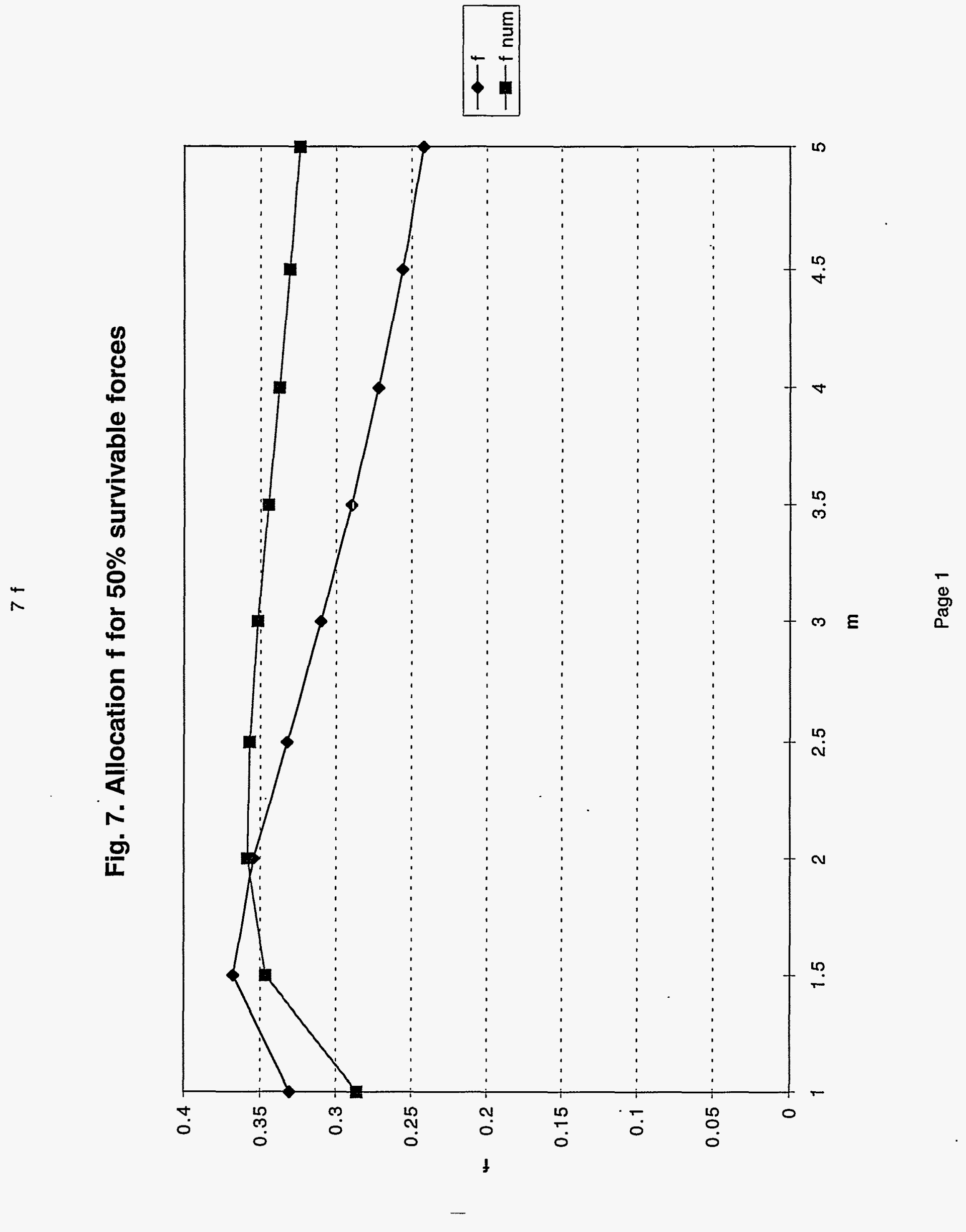




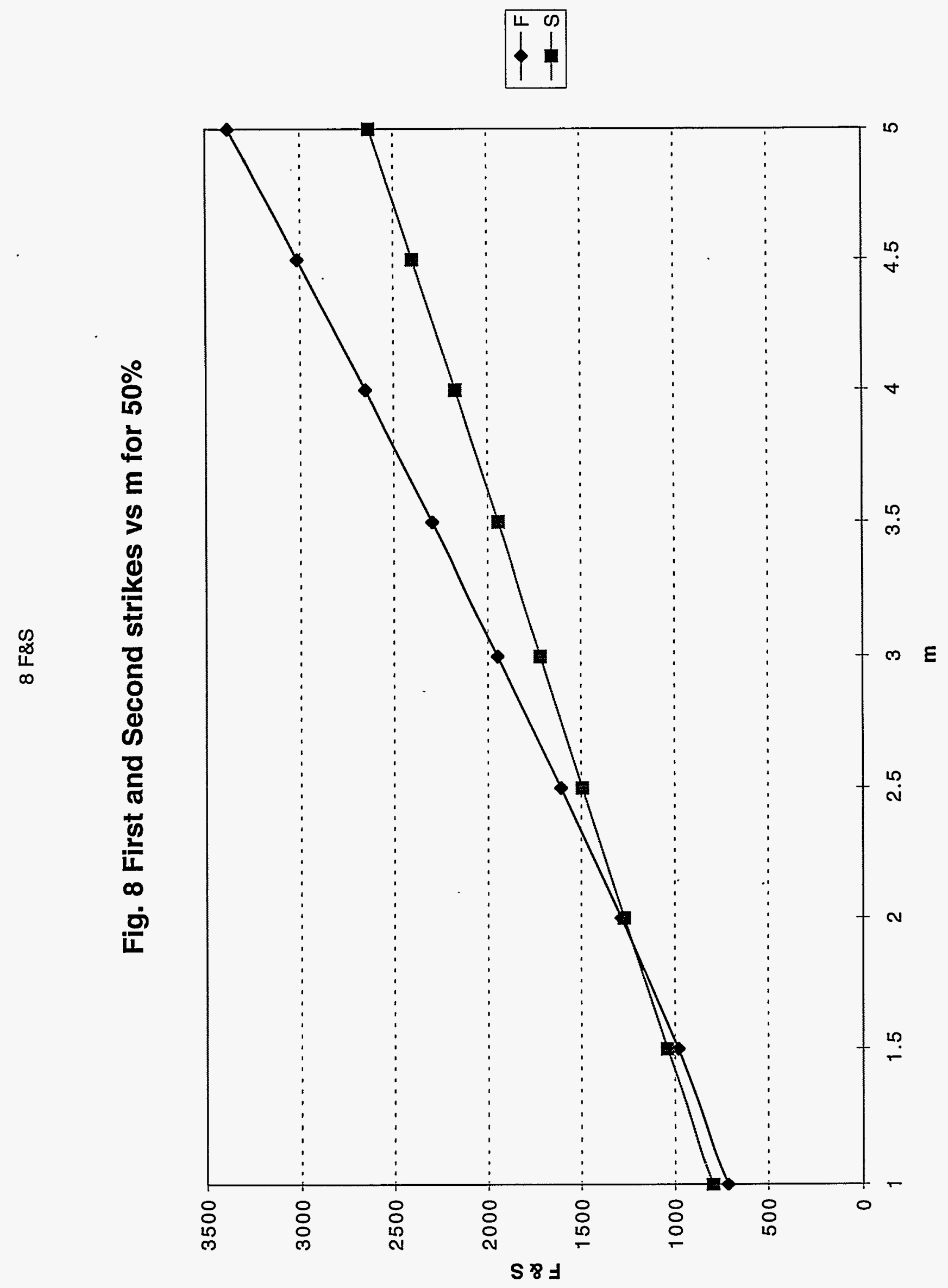



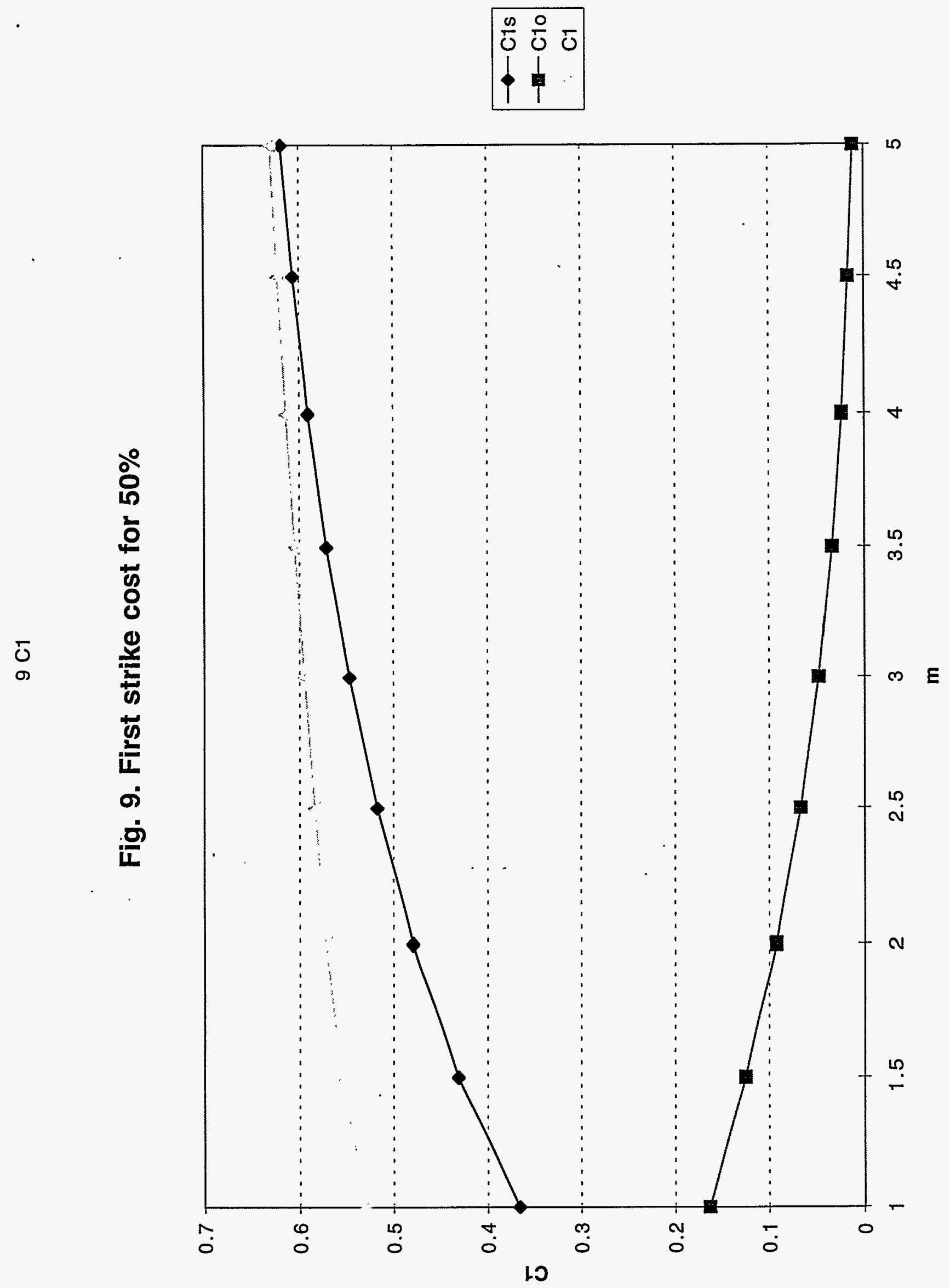

ঙ্ণ 

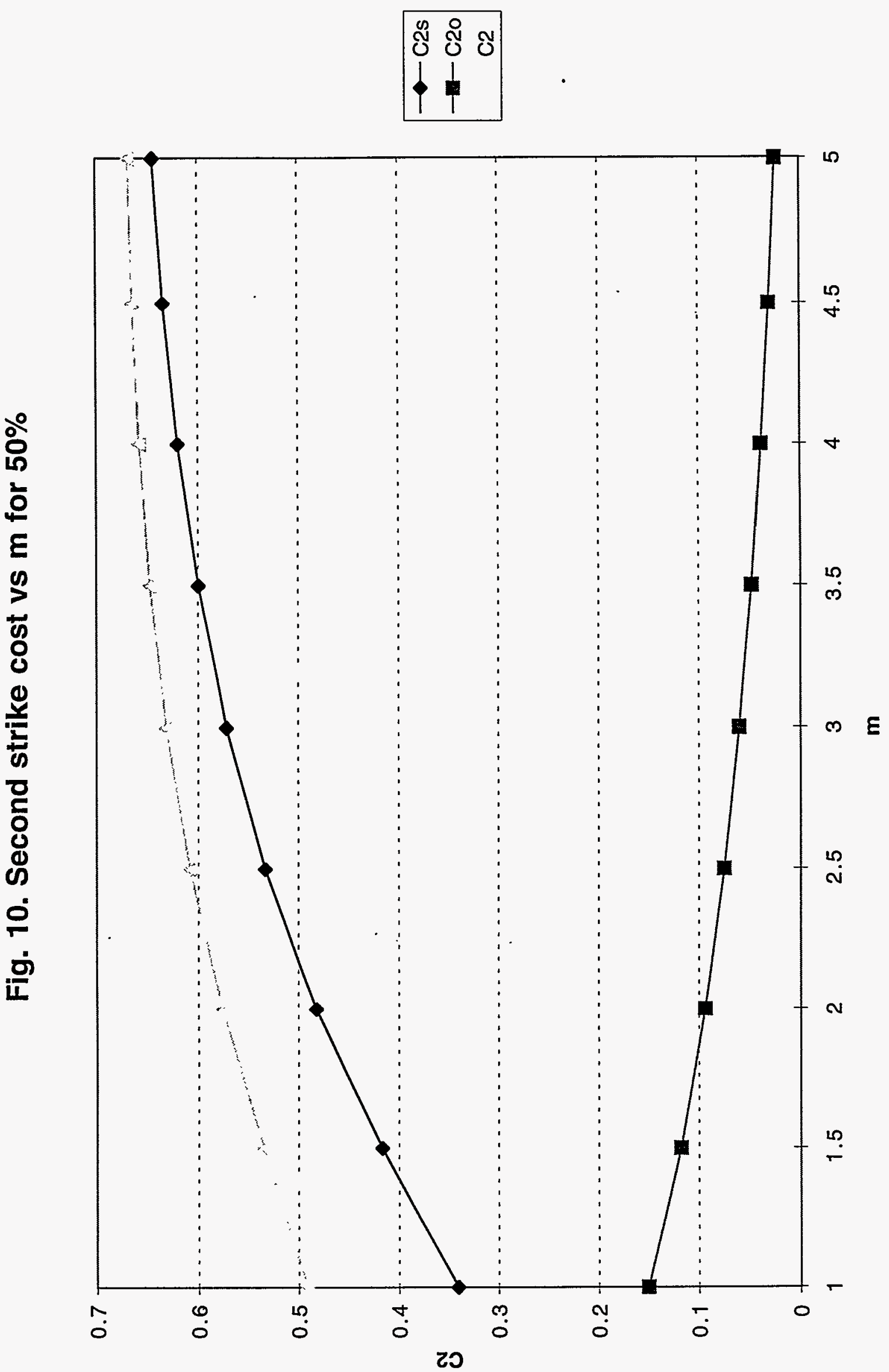

্ֻণ 


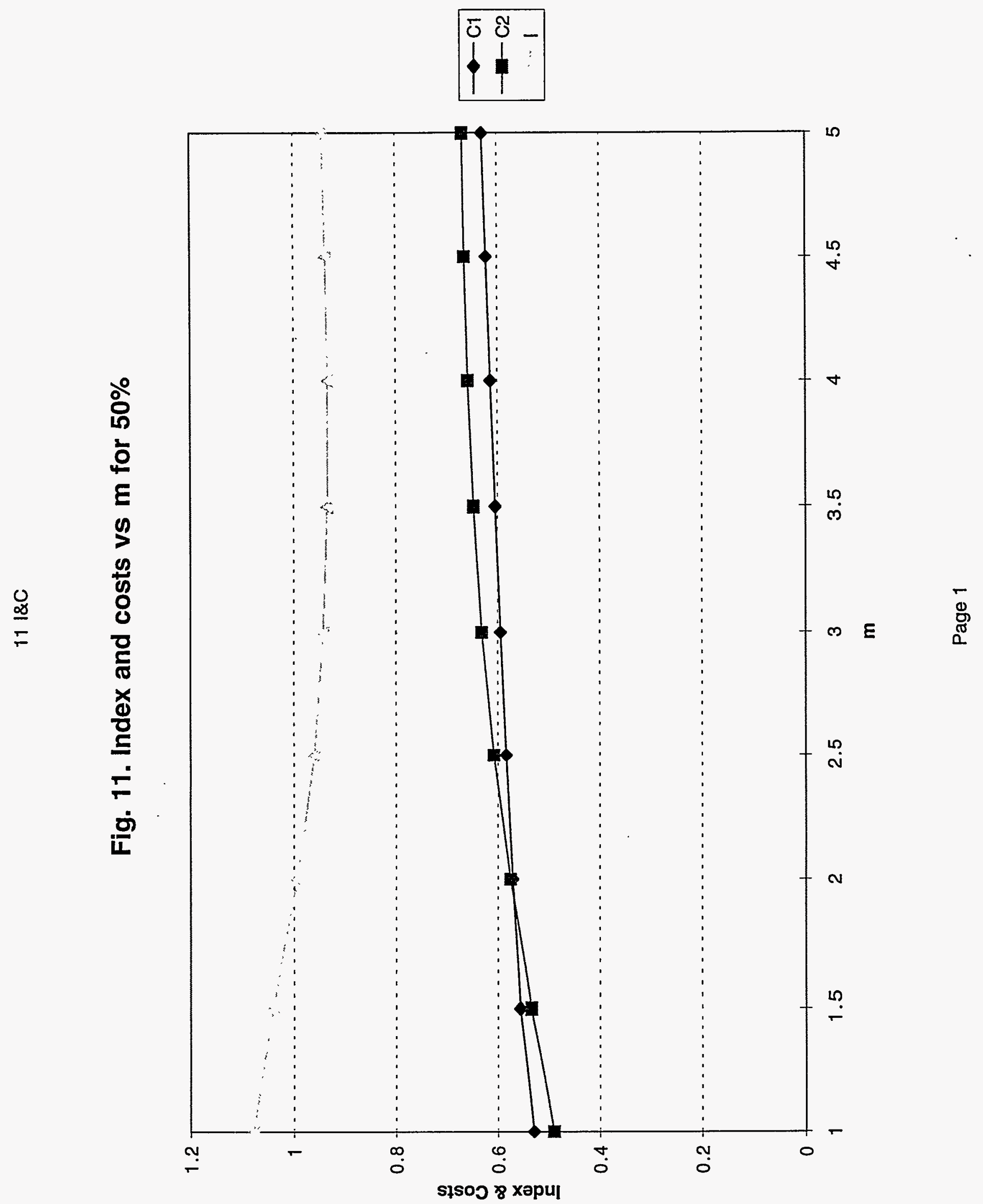


$12 I \vee C 1$

Fig. 12. Index vs first strike cost for $50 \%$

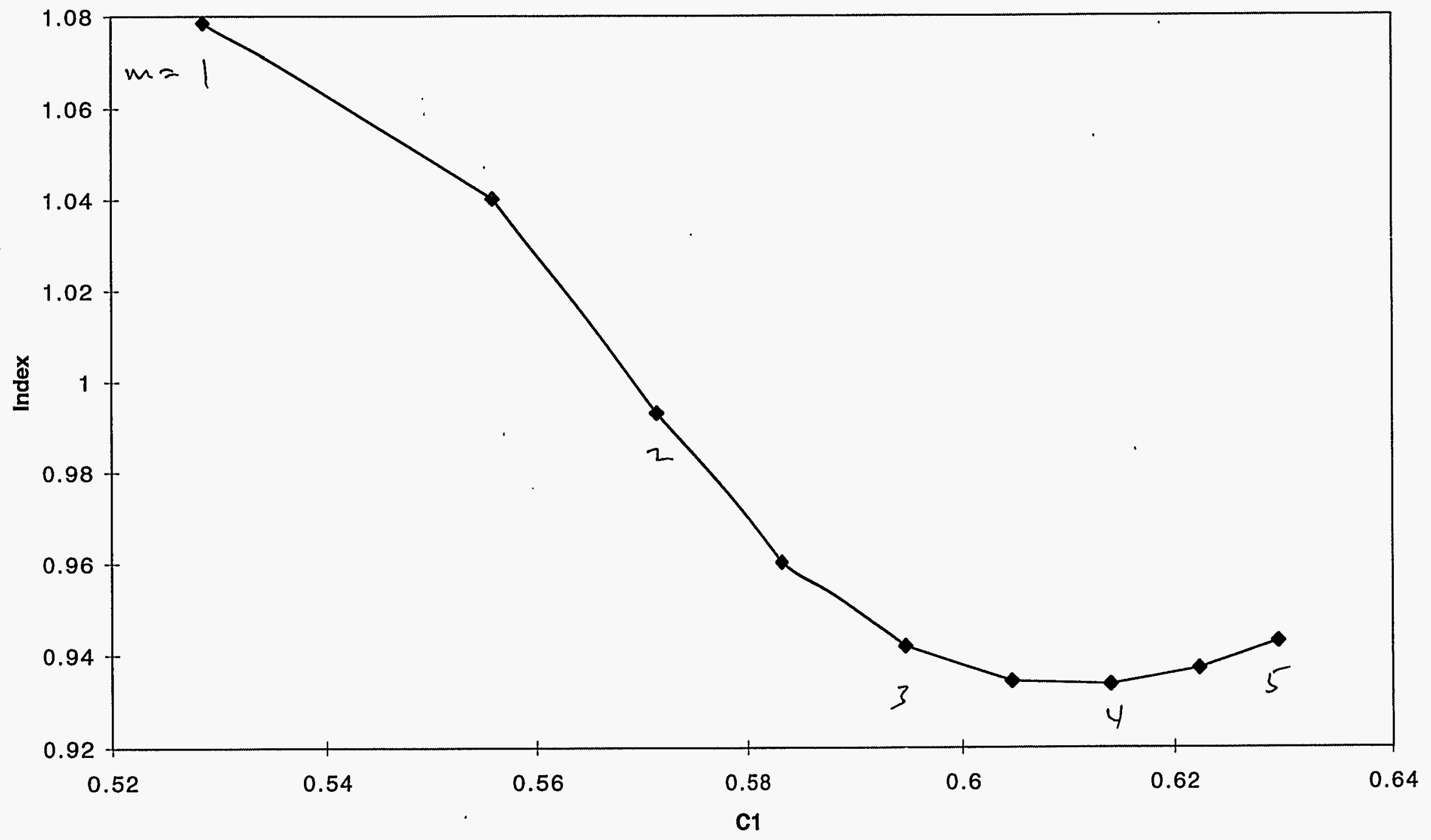

Page 1 